\title{
Adolescents' Relationship between Physical Education and Longitudinal Physical Activity Trends
}

\author{
Alexandra Wiseman'1, Patricia Weir ${ }^{2}$ \\ ${ }^{1}$ Department of Kinesiology, University of Windsor, Windsor, Canada \\ ${ }^{2}$ Office of Quality Assurance, Faculty of Graduate Studies, University of Windsor, Windsor, Canada \\ Email: awiseman@uwindsor.ca, weir1@uwindsor.ca
}

How to cite this paper: Wiseman, A., \& Weir, P. (2017). Adolescents' Relationship between Physical Education and Longitudinal Physical Activity Trends. Advances in Physical Education, 7, 286-302. https://doi.org/10.4236/ape.2017.73023

Received: June 14, 2017

Accepted: August 11, 2017

Published: August 14, 2017

Copyright @ 2017 by authors and Scientific Research Publishing Inc. This work is licensed under the Creative Commons Attribution International License (CC BY 4.0).

http://creativecommons.org/licenses/by/4.0/ (c) (i) Open Access

\begin{abstract}
With physical education (PE) being an avenue to be physically active and learn about health and wellbeing, it is important to understand enrollment trends and physical activity (PA) behaviors among adolescents. The purpose of this study is to examine adolescents' health profiles and gain an understanding of adolescents' perspective of PE. The current study used mixed methodology to examine adolescents' health profiles and gain understanding of their perspectives of PE. Part 1 identified relationships over a two-year period between: PE rating, physical activity (PA), and health variables using data from the $\mathrm{Na}$ tional Longitudinal Survey of Children and Youth (NLSCY). Part 2 examined adolescents' perspectives of PE through four focus groups. Overall, PE was preferred over other subjects by $78 \%$ of participants; and preferring PE predicted higher frequencies of PA, lower BMI, and higher self-es- teem. Enrollment in high school PE was influenced by the environment, gender, course conflicts, and teacher influence. In summary, the majority of adolescents prefer PE; it has an influence on health, and is an avenue for PA. Continued efforts need to be made to increase PE enrollment and participation to ensure the health of young people.
\end{abstract}

\section{Keywords}

Physical Education, Physical Activity, Adolescents, Youth, Teens, Health, Exercise, School, Enrollment

\section{Introduction}

Understanding the impact of the school environment on physical activity (PA) levels is beneficial in creating health promotion strategies; targeting students of 
varying levels of physical fitness. One way to encourage lifelong participation in PA among adolescents is through Physical Education (PE) class. For adolescents who do not participate in sport, or engage in PA outside of school, PE may play a crucial role in keeping them active. The purpose of this study was to examine adolescents' health profiles and gain an understanding of adolescents' perspectives of PE with intentions to utilize the results to provide $\mathrm{PE}$ as a viable option of PA.

The PA guideline for adolescents across Canada and the United States of America is 60 minutes per day (Canadian Society for Exercise Physiology, 2013; U.S. Department of Health \& Human Services, 2013). This amount of PA can help adolescents grow stronger, feel happier, maintain a healthy body weight, improve self-confidence, and learn new skills (Canadian Society for Exercise Physiology, 2013). Additionally, adolescents who engage in PA, have lower body fat (Nassis, Psarra, \& Sidossis, 2005), lower chance of cardiovascular disease (Andersen, Harrow, Sardinha, Froberg, Ekelund, Brage \& Anderssen, 2006), higher self-esteem, greater social skills, lower chance of engaging in health risk behaviors (Aaron, Dearwater, Anderson, Olsen, Krisak, \& LaPorte, 1995), and higher academic achievement (Coe, Pivarnik, Womack, Reeves, \& Malina, 2006; Public Health Ontario, 2010). Conversely, physical inactivity increases chances for 25+ chronic illnesses, including overweight and obesity, and some cancers (Booth \& Lees, 2007). Conversely, adolescents who succumb to physical inactivity are at a higher risk for obesity (Sallis \& Patrick, 1994), a variety of cardiovascular risk factors (Sallis \& Patrick, 1994; Camhi, Phillips, \& Young, 2010), and developing osteoporosis later in life (World Health Organization, 2004). To put this into perspective, in 2007 chronic illnesses were responsible for $75 \%$ of all deaths in Ontario (Active Healthy Kids Canada, 2012).

The aforementioned benefits present concern when the following data are considered. Time spent engaging in moderate to vigorous physical activity (MVPA) declined among females from early to mid-adolescence (5.9 - 4.9 hours/week) to mid- to late-adolescence (5.1 - 3.5 hours/week) (Nelson, Neumark-Sztainer, Hannan, Sirard, \& Story, 2006). Results also showed males' participation showed significant declines from mid- to late-adolescence (6.5 - 5.1 hours/week). Moreover, as a potential result of declining PA rates, the presence of overweight status among adolescents has risen in males from $14 \%$ (1999-2000) to $18.2 \%$ (20032004) and females from $13.8 \%$ (1999-2000) to $16.6 \%$ (2003-2004) (Hedley, Ogden, Johnson, Carroll, Curtin, \& Flegal, 2004). More recently, research has shown $19.8 \%$ of Canadians 5 to 17 years of age (Statistics Canada, 2010) and $33.2 \%$ of Americans 6 to 19 years of age (Fryar, Carroll, \& Ogden, 2014) are considered overweight or obese. When data is compared from 1978/1979 to 2004 for Canadians 2 to 17 years of age considered overweight or obese, the prevalence has increased from 15\% to 26\% (Public Health Agency of Canada, 2012). In addition, World Health Organization (2015) forecasts that youth who are overweight or obese will likely continue to be overweight or obese as adolescents and adults if 
an intervention is not presented.

While studies report an overall decline in PE enrollment for high school students in Ontario (Table 1) (Faulkner, Goodman, Adlaf, Irving, Allison, \& Dwyer, 2007; Hobin, Leatherdale, Manske, Burkhalter, \& Woodruff, 2009), 77.7\% - 86.6\% students who do enroll in PE are meeting the recommended 150 minutes of MVPA per week as per suggestions through the PE curriculum (Dwyer et al., 2006); which further identifies the school as an effective environment for PA. For students who do not participate in sport, or engage in PA outside of school, PE may play a crucial role in keeping them active. Fishburne and Hickson (2005) define PA as the expenditure of energy as a result of bodily movement and emphasizes the important role it plays in the PE curriculum by providing students with a chance to practice and improve a variety of motor skills. The main intention of PE courses in Canada is to assist students in shaping their health behaviours (Gibbons, 2009), by developing skills, and attitudes, vital for engaging an active lifestyle (Fishburne \& Hickson, 2005).

The potential to increase PA levels through PE identifies the school environment as a convenient place to promote healthy behaviours for adolescents (Wechsler, Devereaux, Davis \& Collins, 2000; Biddle, Gorely \& Stensel, 2004; Public Health Ontario, 2010). Physical Education class is a consistent opportunity for students to engage in MVPA (Faulkner et al., 2007), meet Canadian PA recommendations (Trudeau \& Shephard, 2008), and increase PA levels in general (Hobin et al., 2010).

However, the few studies that have observed adolescents' attitudes toward PE uncovered that both males and females negatively viewed long bouts of running, fitness testing, and coeducational classes (Luke \& Sinclair, 1991). When students believed their class promoted competition with too much focus on their mistakes, they were less likely to enjoy class (Ferrer-Caja \& Weiss, 2000). Some males disliked PE because they felt they were unfit, unhealthy, and could not keep up with the class (Luke \& Sinclair, 1991). Moreover, females felt embar-

Table 1. PE enrollment rates in Ontario: 1999-2006.

\begin{tabular}{ccccccc}
\hline \multicolumn{5}{c}{ Faulkner et al. (2007) } & Hobin et al. (2010) \\
\hline Year & 1999 & 2001 & 2003 & 2005 & $1999-2005$ & $2005-2006$ \\
\hline Males & 72.3 & 69.8 & 71.8 & 65.2 & 69.2 & $\%$ \\
Females & 68.2 & 55.7 & 68.7 & 55.7 & 62.4 & 67.0 \\
Grade 9 & 81.5 & 71.5 & 78.8 & 70.6 & 75.4 & 57.5 \\
Grade 10 & 71.7 & 64.0 & 67.8 & 57.8 & 64.3 & 73.4 \\
Grade 11 & 65.1 & 56.1 & 67.5 & 60.2 & 63.1 & 63.2 \\
Grade 12 & 58.1 & 53.6 & 66.4 & 54.5 & 59.2 & 58.7 \\
Total & 70.3 & 63.1 & 70.2 & 60.3 & & 51.3 \\
\hline
\end{tabular}


rassed, self-conscious, pressured, and began disliking PE when they started being evaluated on their athletic ability (van Daalen, 2005).

Although adolescents' PA levels and PE enrollment are declining, there are some PE classes with high enrollment rates and positive student feedback. Research on successful female PE classes suggested designing different courses to specific populations of students, assessing students on tasks that would be performed in real-world settings, and fostering a safe and healthy learning environment (Gibbons, 2009). Furthermore, research on both genders found when students feel their success is attainable through hard work and an interest in learning, they feel more invested in the PE class as they understand they have control of their achievement (Standage, Duda, \& Ntoumanis, 2003). In order to identify the issues surrounding adolescent's participation in high school PE class the current multi-dimensional study was conducted.

The purpose of this study was: 1) to identify adolescents' PE rating among other subjects and identify it as a predictor of PA levels and health variables longitudinally; 2) to identify the relationship of Non-School-Based PA and health variables longitudinally; 3 ) to identify changes in health variables longitudinally; and, 4) to gain insight on adolescents' perspectives of PE.

\section{Methods}

This study utilized a mixed methodology and was completed in two parts. Part 1 addressed components 1 through 3 using quantitative analyses of data from the National Longitudinal Survey of Children and Youth (NLSCY) as conducted by Statistics Canada (Appendix A). Part 2 addressed component 4 through qualitative analyses of focus groups conducted at high schools within Windsor-Essex County, Ontario, Canada. Research Ethics Board approval from the University of Windsor was obtained, and participant consent and parental consent were obtained for Part 2 of this study.

$\underline{\text { Part } 1}$

Participants. Participants from Cycle 7 (C7) were Canadian adolescents (range $=12-15$ years, $\underline{\mathrm{M}}=13.64$ years, $\mathrm{SD}=1.15$ ), and participants from Cycle 8 (C8) were the same adolescents two years later (range $=14-17$ years, $\underline{M}=$ 15.72 years, $\mathrm{SD}=1.16$ ). The overall sample size was 4963 (males $=51.6 \%$, females $=48.4 \%$ ); however, due to differences in the questions included in Cycles 7 and 8 , the final samples for analyses ranged from 1713 to 4.82 .

Instruments. The NLSCY is a longitudinal study conducted by Statistics Canada (2010) with the goal of observing the development of Canadians from infancy to adulthood. Data from Cycle 1 was collected in 1994/1995 and data has been collected every two years until Cycle 8 in 2008/2009. The participants in the NLSCY were selected from households that were already being sampled by Statistics Canada's Labour Force Survey (Statistics Canada, 2010). The NLSCY gathered self-reported data on factors influencing a child's social, emotional, and behavioural development and to monitor the impact of these factors on a child's development over time. Specifically, this data were derived through a self-com- 
pleted paper questionnaire of participants between the ages of 12 and 17 years across Canada. The questionnaire was self-completed, sealed in an envelope to ensure confidentiality, and returned to the interviewer (Statistics Canada, 2010). At the time of data analysis, data from $\mathrm{C} 7$ and $\mathrm{C} 8$ were not available on a public use micro data file and approval from Statistics Canada was obtained.

Procedure. A predictor variable was constructed from a series of questions from the NLSCY C7 asking: "How do you like the following subjects: Math, English, French, Science, PE, Arts?" Participants chose one of five answers (I hate it, I don't like it very much, I like it a little, I like it a lot, I don't take it). Since very few participants responded with "I don't take it", this answer was omitted for analysis purposes. To construct the predictor variable from students' ratings of PE when compared to other subjects, the overall mean for students' rating of Math, Science, English, French, and Arts was calculated. This value was then subtracted from the mean rating of PE. The difference between these means represented participants' preference for PE over the mean rating of other subjects, or participants' preference of other subjects over PE. Upon reviewing the range, these scores were collapsed into three categories of preferences in considering PE: 1) prefers other subjects over PE; 2) tie between PE and other subjects; and 3) prefers PE over other subjects. Moreover, the PE rating in relation to other subjects was computed into a new variable and used as a predictor variable for multiple regression analyses. Three variables pertaining to PA during the past 12 months outside of school were collapsed into one overall Non-SchoolBased PA (NSBPA) (range: 3 - 12) variable for each cycle and the C7 NSBPA variable was used as a predictor for multiple regression analyses.

Five health behaviors and outcomes from $\mathrm{C} 7$ and C8 were examined as dependent variables: NSBPA (range $=3$ - 12), School-Based PA (SBPA) (range $=3$ 12), BMI (range $=1-3$ ), "I like the way I look" (range $=1-5$ ) and Health Status (range $=1-5)$.

Data Analyses. Multiple regression analyses were used to determine if $\mathrm{PE}$ rating and C7 NSBPA separately predicted NSBPA, SBPA, BMI, and "I like the way I look" from C8. The standardized coefficient, Beta $(\beta)$, value was used to indicate how many standard deviations the outcome variables changed when the predictor variable increased by one standard deviation; this value is also representative of the effect size.

To determine a change in health behaviors over two years, the Wilcoxon signedrank test was used to compare C7 to C8. Variables of interest included: NSBPA, Health Status, "I like the way I look", and BMI. For these tests, effect sizes (r) were calculated to determine the power of the relationship. This was done by dividing the Z-value by the square root of $\mathrm{N}$ (Cohen, 1988).

IBM Statistics Package for the Social Sciences (SPSS) 20 was used for all data analysis (IBM Corp, 2011).

$\underline{\text { Part } 2}$

Participants. Thirty two high school students including males $(\mathrm{n}=13)$ and females $(\mathrm{n}=19)($ range $=14-19 ; \underline{\mathrm{M}}=15.63, \mathrm{SD}=1.72)$ participated in Part 2. 
Focus groups consisted of 7 to 9 students, and were separated into grade 9 ( $\mathrm{n}=2$ focus groups) and grade $11 / 12$ ( $n=2$ focus groups). Students had enrolled in high school PE at least once to meet the mandatory Ontario provincial requirements of one credit and were randomly selected on a volunteer basis through the principals and PE departments within the Greater Essex County and WindsorEssex Catholic district school boards.

Instruments. A semi-structured question guide (Appendix B) was prepared by the researcher after a thorough review of literature and meetings with members of the local school board. Inventories were also developed with a list of potentially influential factors to students' PE experiences to stimulate discussion.

Procedure. Focus groups were moderated by the researcher and were $75 \mathrm{mi}-$ nutes in length. Each session began with less structured questions that introduced the topic of PE and progressed into more specific questions (Kruger, 1998a).

Data analyses. First, the audio recordings of each focus group were transcribed verbatim. Following previous work (Kruger, 1998b; Tesch, 1990), interviews were separated into meaning units that highlighted relevant information within and across focus groups. In order to discover prevalent themes from the data, similarities, differences, and repetitions were identified (Ryan \& Bernard, 2003). Some categories were combined to strengthen data groupings and the importance of each category was considered based on information most useful for promoting health behaviors among adolescents.

\section{Results}

\section{Part 1}

Physical Education rating. When the $\mathrm{PE}$ rating variable $(\underline{\mathrm{M}}=2.61, \mathrm{SD}=.76)$ was constructed, frequencies showed, $17.0 \%$ preferred other subjects over PE, 4.9\% tied between other subjects and $\mathrm{PE}$, and $78.1 \%$ preferred $\mathrm{PE}$ over other subjects. Females $(\underline{\mathrm{M}}=2.47, \mathrm{SD}=.853)$ rated $\mathrm{PE}$ lower when compared to males $(\underline{\mathrm{M}}=2.75, \mathrm{SD}=.626)($ Table 2$)$. Multiple regression analyses showed $\mathrm{PE}$ rating significantly predicted NSBPA [R2 $=.019, \mathrm{~F}(11,1762)=3.165, p<.05]$, SBPA $[\mathrm{R} 2=.048, \mathrm{~F}(11,2082)=9.582, p<.05], \mathrm{BMI}[\mathrm{R} 2=.018, \mathrm{~F}(11,3331)=5.441, p$ $<.05]$, and the "I like the way I look" variable $[\mathrm{R} 2=.041, \mathrm{~F}(11,3528)=13.827, p$ $<.05$ ] in C8 (Table 2). Therefore, if participants preferred PE over other subjects they reported a higher frequency of PA per week, lower BMI, and a more favorable "I like the way I look" rating two years later.

Cycle 7 Non School Based Physical Activity. Frequencies showed overall mean NSBPA decreased from $\mathrm{C} 7$ to $\mathrm{C} 8$, and when NSBPA was deconstructed, the mean for each NSBPA variable also decreased from $\mathrm{C} 7$ to $\mathrm{C} 8$ indicating that it was not a single variable responsible for overall mean decrease (Figure 1). Multiple regression analyses identified C7 NSBPA as a significant predictor for C8 NSBPA $[\mathrm{R} 2=.213, \mathrm{~F}(11,1792)=44.154, p<.05]$, Health Status $[\mathrm{R} 2=.066$, $\mathrm{F}(11,1820)=11.689, p<.05]$, BMI $[\mathrm{R} 2=.038, \mathrm{~F}(11,1702)=6.169, p<.05]$, and "I like the way I look" [R2 $=.062, \mathrm{~F}(11,1828)=10.992, p<.05]$ (Table 3). This 
Table 2. PE rating predicting NSBPA and SBPA.

\begin{tabular}{cccccccccc}
\hline \multirow{3}{*}{ Control } & \multicolumn{7}{c}{ Outcome } \\
\cline { 2 - 9 } & $\begin{array}{c}\text { C8 Non-School-Based } \\
\text { Physical Activity }\end{array}$ & \multicolumn{2}{c}{$\begin{array}{c}\text { C8 School-Based } \\
\text { Physical Activity }\end{array}$} & C8 BMI & \multicolumn{2}{c}{$\begin{array}{c}\text { C8 “I like the way I } \\
\text { look" }\end{array}$} \\
\cline { 2 - 10 } & $\operatorname{Beta}(\beta)$ & $\operatorname{Sig}(p)$ & $\operatorname{Beta}(\beta)$ & $\operatorname{Sig}(p)$ & $\operatorname{Beta}(\beta)$ & $\operatorname{Sig}(p)$ & $\operatorname{Beta}(\beta)$ & $\operatorname{Sig}(p)$ \\
\hline PE Rating & .083 & $.001^{*}$ & .143 & $.000^{*}$ & .063 & $.000^{*}$ & .056 & $.001^{*}$ \\
\hline
\end{tabular}

${ }^{*}$ Statistical Significance.

Table 3. C7 NSBPA predicting NSBPA and health status.

\begin{tabular}{cccccccccc}
\hline \multirow{3}{*}{ Control } & \multicolumn{9}{c}{ Outcome } \\
\cline { 2 - 9 } & $\begin{array}{c}\text { C8 Non-School-Based } \\
\text { Physical Activity }\end{array}$ & \multicolumn{2}{c}{ C8 Health Status } & C8 BMI & \multicolumn{2}{c}{$\begin{array}{c}\text { C8 “I like the way I } \\
\text { look" }\end{array}$} \\
\cline { 2 - 10 } & $\operatorname{Beta}(\beta)$ & $\operatorname{Sig}(p)$ & $\operatorname{Beta}(\beta)$ & $\operatorname{Sig}(p)$ & $\operatorname{Beta}(\beta)$ & $\operatorname{Sig}(p)$ & $\operatorname{Beta}(\beta)$ & $\operatorname{Sig}(p)$ \\
\hline C7 NSBPA & .454 & $.000^{*}$ & .176 & $.000^{*}$ & .071 & $.003^{*}$ & .110 & $.000^{*}$ \\
\hline
\end{tabular}

*Statistical significance.

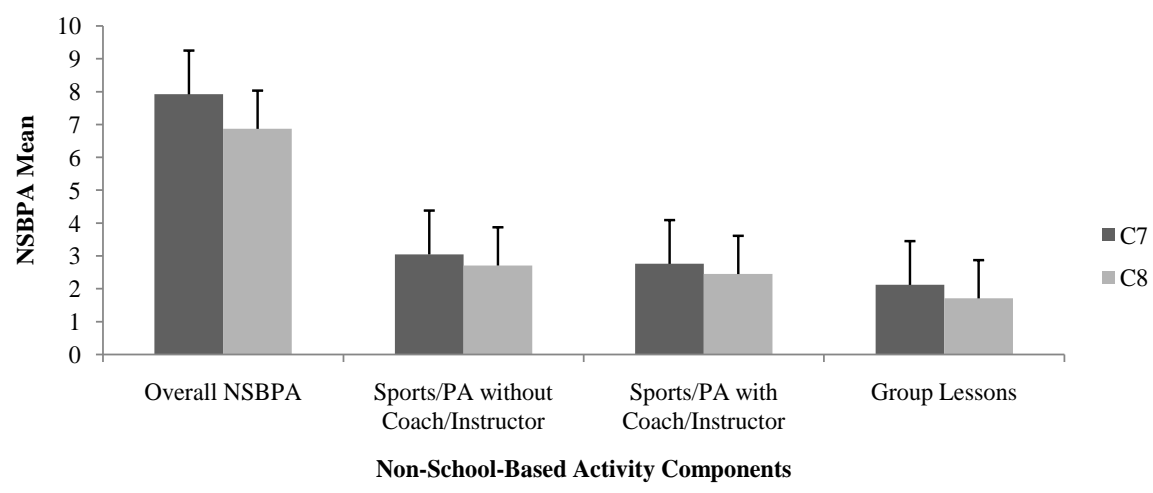

Figure 1. Means for NSBPA with standard error bars.

indicates, if participants reported higher frequencies of NSBPA per week in C7 they reported higher frequencies of NSBPA per week, higher Health Status, lower BMI, and a more favorable "I like the way I look" rating in C8. It should be noted that the relationship between C7 and C8 NSBPA was the most positive relationship through the multiple regression analyses inferring that if participants engaged in NSBPA in C7 they were more likely to engage in NSBPA two years later in C8.

Health variables. Wilcoxon signed rank tests showed significant change between NSBPA, Health Status, BMI, but not "I like the way I look" (Table 4). Participants had lower levels of NSBPA in C8 when compared to C7. Health Status and BMI can be explained by the concept that a higher number of participants changed their score by more than one value in the direction of a negative health outcome, and fewer participants changed their score by one in the direction of a positive health outcome. For example, a higher number of participants went from Normal Weight to Obese, compared to a lower number of participants who went from Obese to Overweight or Overweight to Normal Weight. 
Table 4. Medians and standard deviations for Wilcoxon signed-rank variables.

\begin{tabular}{|c|c|c|c|c|c|c|}
\hline \multirow{2}{*}{ Variable } & \multirow{2}{*}{ Wilcoxon } & \multicolumn{2}{|c|}{$M$} & \multicolumn{2}{|c|}{ SD } & \multirow[t]{2}{*}{$\operatorname{Sig}(p)$} \\
\hline & & $\mathrm{C} 7$ & $\mathrm{C} 8$ & $\mathrm{C} 7$ & $\mathrm{C} 8$ & \\
\hline NSBPA & $\mathrm{Z}=-17.27 . p<.05, \mathrm{r}=-.41$ & 8.0 & 7.0 & 2.21 & 2.22 & $<.000$ \\
\hline Health Status & $\mathrm{Z}=-5.460, p<.05, \mathrm{r}=-.13$ & 4.0 & 4.0 & .81 & .89 & $<.000$ \\
\hline BMI & $\mathrm{Z}=2.457, p<.05, \mathrm{r}=-.44$ & 1.0 & 1.0 & .56 & .55 & .014 \\
\hline $\begin{array}{l}\text { "I like the way I } \\
\text { look" }\end{array}$ & $\mathrm{Z}=-1.016, p>.05, \mathrm{r}=-.01$ & 4.0 & 4.0 & 1.04 & 1.01 & .310 \\
\hline
\end{tabular}

r represents effect size.

\section{$\underline{\text { Part } 2}$}

Focus group data analyses yielded multiple themes: class environment, gender differences, course conflict, and students' suggestions. Of these themes, teacher influence within class environment and course conflict were among the most heavily discussed. These themes also consisted of different meaning units represented by quotes from the focus group sessions (Table 5).

Class environment. Participants identified that the class environment was highly influential to their PE experience and consisted of: the physical and social environment, participation and personalities, teacher influence, and evaluation. All participants agreed that when a teacher participated and/or showed interest in the course the students felt more motivated and excited about the class. Overall, participants indicated a heavy emphasis on teacher influence as a deciding factor for whether they wanted to enroll again or not.

Gender differences. Females who had previously identified themselves as athletic suggested that co-ed classes did not bother them because it gave them an opportunity to be challenged. Most females also agreed that it was fun to mix once in a while but they would generally prefer a same-sex class because males were viewed as overly competitive. Females enjoyed the openness of same-sex $\mathrm{PE}$ because it gave them an opportunity to ask questions throughout the health unit without feeling judged by their male schoolmates; whereas males wished it was a separate course.

Course conflicts. Course conflicts were discussed as a highly influential barrier of PE enrollment across all participants. Many participants who wished to take PE indicated that they did not have room in their schedule due to prerequisites for future classes. Prerequisites were identified as necessary not only for senior years of high school but for university acceptance. Physical Education was beneficial for getting active but was not considered useful, relevant, or practical, in comparison to other courses. With limited timetable space in grade 10, students were forced to choose carefully between many options. This theme was consistently agreed upon and had a large influence on students' future enrollment.

Students' suggestions and insight. Across all focus groups, participants made suggestions for what may increase PE enrollment. Participants discussed 
Table 5. Focus group quotes.

Class Environment

Physical Environment

"You get outside the classroom environment and it's almost like a totally different environment. You're actually doing something instead of just sitting there." (2, 04/09/2013)

"...participation, if I know it's going to be a gym class where no one is going to participate then it's not going to

Participation and Personalities be a good gym class." (1,03/07/2013)

"Some people take it too seriously; that drives me crazy; people who don't take it seriously at all and people who take it too seriously." (4, 03/26/2012)

Emotions

"Embarrassment and discomfort...I always feel awkward playing sports because I don't know what I'm doing so I'm afraid to embarrass myself." (2, 03/26/2013)

"Our gym teacher is awesome; you're so excited to be there...She just pushes you and it's fun, but in the opposite if you have a teacher who's hardcore, makes you feel bad, doesn't encourage you, is terrifying, you don't want to be there." (5, 04/03/2013)

Teacher Influence

"When I was in grade 9 I really enjoyed my teacher, he was really funny and made it really comfortable as a class...But then in grade $10 \mathrm{I}$ had a teacher who wasn't so authoritarian and kind of let everything slip by, so it made it more uncomfortable...That was the reason I didn't take it anymore." (3, 03/26/2013)

“...it's harder when they mark on skill, because you're going to get a lower mark.” (4, 03/26/2013)

Evaluation "In grade 9, I wasn't very good at gym, but I always participated, and came with my jersey, and I tried, so I got like an $88 . "(3,03 / 26 / 2013)$

Gender Differences

Co-Ed versus Same-Sex Class

Course Conflicts

\section{Students' Suggestions}

Course Design

Options

Emphasis
Male: "We were playing soccer and two girls went to the middle of the field and started picking flowers...as long as they try and they try to challenge us, or challenge themselves, I would share the ball." (2, 04/09/2013)

Females: "Then we would play with girls playing each other and boys playing each other and it was so much more fun because we got to touch the ball and would pass it to each other." $(9,04 / 09 / 2013)$

"I would hate being in a co-ed gym class. The things that come up, if guys were there it would make it so awkward, we wouldn't be able to be as fun and open...I just think girls wouldn't be as confident." $(5,4 / 03 / 2013)$

"Gym is something you can get active in and they had prerequisite courses they needed to focus on."

$(1,03 / 07 / 2013)$

"I personally didn't take it again after grade 9 even though I always liked gym and everything because there were so many courses that I wanted to take in grade 10 that would be prerequisite courses for future courses."

$(2,03 / 26 / 2013)$

"There are other prerequisites you need for other career paths. So maybe if they were to take out different set in stone classes that not everyone wants...I think gym is more important..." $(4,04 / 03 / 2013)$

"I think if it was a requirement, there should be different tiers of classes, the serious kids could take it, and the kids who just want to take it for fun would take a different class." (3, 03/26/2013)

"At the beginning of the semester we give our teacher $\$ 25$ and we pick five things we want to do, so we went skating, we have yoga, hip-hop, and instructors come in. One of the most fun things I've ever done in my life is Zumba!" (5, 04/03/2013)

"If they keep that up, what they learned in gym, about getting in shape and working out, it'll become a habit and that's the best thing, that's what you want for the rest of your life." (3, 03/07/2013)

the idea of competitive versus non-competitive classes, different activity options (e.g., self-defense and yoga), field trips, specialized guest instructors, and more activity choices. It was suggested that more students may enroll if they know they would be accompanied by other students who were interested in the same activities as them and are not overly competitive. Furthermore, participants 
from different focus groups suggested conducting a survey in which teachers could obtain an idea of what activities to include in the course. Lastly, when participants were asked what they would emphasize if their job was to get students to enroll in PE, they agreed that learning to be active is something that they can use for the rest of their lives.

\section{Discussion}

This study aimed to identify the relationship between PE rating, NSBPA, a variety of health variables, and adolescents' perspectives of $\mathrm{PE}$ at the secondary school level. Although PE rating is a predictor of NSBPA and both longitudinally predict a variety of health variables, Canadian adolescents are engaging in less NSBPA as they age. Adolescents preferred PE over other subjects (78\%), which suggested greater NSBPA levels, lower BMI, and higher self-esteem, but PE enrollment continues to decline (Dwyer et al., 2006; Faulkner et al., 2007; Hobin et al., 2009).

Consistent with previous research, PE rating and C7 NSBPA predicts lower BMI (Datar \& Sturm, 2004; Camhi, Phillps, \& Young, 2010) and self-esteem (Luke \& Sinclair, 1991). Depending on the structure of the class, PE may be a negative experience in which students are exposed by their lack of ability leading to negative perceptions (Luke \& Sinclair, 1991; Gibbons, 2009; Allison, Dwyer, Goldenberg, Fein, Yoshida, \& Boutilier, 2005; Bauer, Yang, \& Austin, 2004). Focus group results explored the suggestions of having classes which are divided by level of competition. This finding is similar to previous research suggesting students prefer to compete against themselves rather than peers and avoid pursuing PA opportunities where overly competitive peers would be present (Allison et al., 2005). This suggestion gives students who are less skilled an opportunity to participate with others of similar skill level. Participants also suggested the class environment should be an avenue students can enjoy themselves and show support and encouragement. The social environment is important as many students indicated they enjoyed the opportunity to spend time with friends; which is supported by previous research on PA (Allison et al., 2005) and PE (Bauer et al., 2004). The predictive nature of C7 NSBPA with C8 NSBPA emphasizes the importance of creating a positive experience with PA, potentially through PE, early in adolescence. This study also identified that adolescents are generally less active, which is supported by research suggesting as age increases PA levels decrease (Active Healthy Kids Canada, 2012; Camhi et al., 2010). It is alarming to consider that this trend may persist and they will become less healthy into adulthood.

While the quantitative data suggest that PE is the preferred academic subject, and that participation in PE is related to healthy behaviours it is puzzling why $\mathrm{PE}$ enrollment decreases. One of the most influential factors discussed, were teachers' influences on the PE experience (Luke \& Sinclair, 1991; van Daalen, 2005; Gibbons, 2009). Students spoke highly of teachers who were outgoing and encouraged goal setting. Moreover, students felt that if the teacher was disen- 
gaged, authoritarian, and did not give positive feedback; they did not have an enjoyable experience.

Students identified other courses in their schedule as a barrier to PE enrollment. Students either wanted to take other courses to explore potential careers or needed specific courses as prerequisites for university. While PE was considered less useful when compared to other options; some students agreed courses could be replaced by PE. Whether the decision was driven through curiosity, academic pressure, or parental pressure (Hobin et al., 2009; Allison et al., 2005), students' schedules did not always allow for PE. Overall, students identified having greater variety and the opportunity to contribute their input as positive contributors to the PE experience (Luke \& Sinclair, 1991; Gibbons, 2009).

\section{Limitations}

Due to the inconsistency of questions asked from $\mathrm{C} 7$ to $\mathrm{C} 8$, it was not possible to analyze a potential link between PE and SBPA, or a change in SBPA levels. Selfreport may also present a limitation as participants are asked to identify their own PA levels and health related responses. Also, although participants generally spoke freely about their PE experiences, participants may have abstained from delving deeper into their personal opinions during focus groups.

\section{Conclusion}

Physical Education is an avenue for PA; it has predictive ability with PA and health variables, and there is mass preference for PE. The use of PE rating as a predictor variable is a unique contribution to the literature. PE rating predicts positive health outcomes and highlights that students in fact enjoy PE classes. Despite the affinity for PE students display, enrollment is declining.

School provides a safe, controlled and inclusive environment for all students despite their family influences (Faulkner et al., 2007), socioeconomic status, gender, and race (van Daalen, 2005). The importance of the school environment in influencing health behaviours among adolescents is not a new development. School plays a vital role in promoting PA and shaping health behaviours to carry into adulthood; specifically PE is a good predictor of tracking PA from adolescence into adulthood (Trudeau, Laurencelle, Tremblay, Rajic, \& Shephard, 1999). The school environment should be taken advantage of by health advocates, administrators, educators, parents, and students on the quest for a healthier lifestyle. High school students who attend PE class regularly reported healthier eating behaviours (e.g. higher intake of fruit and vegetable, and lower intake of soda) and less time spent watching television during the week (Tassitano, Barros, Tenório, Bezerra, Florindo, \& Reis, 2010).

Given the popularity of $\mathrm{PE}$ over other subjects, PE continues to be a viable avenue to promote PA (Public Health Ontario, 2010). Physical Education is free of charge, will afford students with high school credits, and can be provided as a regular part of their semester. More importantly, it is a class in which students can engage in PA, learn about health related topics, and develop new skills. 
These additional topics, such as but not limited to: sexual health, mental health, and healthy relationships are not found elsewhere in the secondary school curriculum and would be an added bonus to the benefits that the adolescents would receive by engaging in $\mathrm{PA}$ in a structured and safe environment. Overall, there is a potential chain reaction that begins in early adolescence through $\mathrm{PE}$ experience and PA levels. This chain reaction can be negative or positive depending on adolescents' enrollment in PE and frequency of participation in PA. This does not imply that students should not enjoy other subjects taught in the school system, but PE courses should be considered an important part of the educational experience.

Adolescence is a highly influential time to shape healthy habits and facilitate positive health behaviours. As we know, adolescents spend majority of their time at school which suggests it is an influential environment (Besançon, Fenouillet, \& Shankland, 2015). Schools can make individual changes to influence adolescents' physical activity (PA) levels to accommodate for the declining Physical Education (PE) enrollment through utilizing themes from this study. Administration, department heads, and teachers can consider what can be done to bridge the gap between the benefits of PA through PE and the students who do not wish to enroll. A further understanding of what prevents students from enrolling in PE will provide groundwork in moving forward with PE promotion.

\section{Acknowledgements}

Kelly Carr, PhD Candidate, Department of Kinesiology, University of Windsor. Dan Edelstein, Data Specialist, University of Windsor. Kristy Thompson, Data Specialist, University of Windsor. Dr. Nancy McNevin, Professor, Department of Kinesiology, University of Windsor. Windsor Essex Catholic District School Board, Windsor, Ontario. Greater Essex District School Board, Windsor, Ontario. Canadian Society for Psychomotor Learning and Sport Psychology Conference (2013), Kelowna, British Columbia

\section{References}

Aaron, D. J., Dearwater, S. R., Anderson, R., Olsen, T., Krisak, A. M., \& LaPorte, R. E. (1995). Physical Activity and the Initiation of High-Risk Health Behaviours in Adolescents. Medicine and Science in Sports and Exercise, 27, 1639-1645.

https://doi.org/10.1249/00005768-199512000-00010

Active Healthy Kids Canada (2012). The Active Healthy Kids Canada Report Card on Physical Activity for Children and Youth. Toronto, ON: Active Healthy Kids Canada.

Allison, K. R., Dwyer, J. J., Goldenberg, E., Fein, A., Yoshida, K. K., \& Boutilier, M. (2005). Male Adolescents' Reasons for Participating in Physical Activity, Barriers to Participation, and Suggestions for increasing Participation. Adolescence San Diego, 40, 155.

Andersen, L. B., Harro, M., Sardinha, L. B., Froberg, K., Ekelund, U., Brage, S., \& Anderssen, S. A. (2006). Physical Activity and Clustered Cardiovascular Risk in Children: A Crosssectional Study (The European Youth Heart Study). The Lancet, 368, 299-304. https://doi.org/10.1016/S0140-6736(06)69075-2 
Bauer, K. W., Yang, Y. W., \& Austin, S. B. (2004). "How Can We Stay Healthy When You'Re Throwing All of This in front of Us?” Findings from Focus Groups and Interviews in Middle Schools on Environmental Influences on Nutrition and Physical Activity. Health Education \& Behavior, 31, 34-46. https://doi.org/10.1177/1090198103255372

Besançon, M., Fenouillet, F., \& Shankland, R. (2015). Influence of School Environment on Adolescents' Creative Potential, Motivation and Well-Being. Learning and Individual Differences, 43, 178-184. https://doi.org/10.1016/j.lindif.2015.08.029

Biddle, S. J. H., Gorely, T., \& Stensel, J. (2004). Health-Enhancing Physical Activity and Sedentary Behaviour in Children and Adolescents. Journal of Sports Sciences, 22, 679-701.

Booth, F., \& Lees, S. J. (2007). Fundamental Questions about Genes, Inactivity and Chronic Diseases. Physiological Genomics, 28, 146-157.

https://doi.org/10.1152/physiolgenomics.00174.2006

Camhi, S. M., Phillips, J., \& Young, D. R. (2010). The Influence of Body Mass Index on Long-Term Fitness from Physical Education in Adolescent Girls. Journal of School Health, 81, 409-416. https://doi.org/10.1111/j.1746-1561.2011.00609.x

Canadian Society for Exercise Physiology (2013). Canadian Physical Activity Guidelines. Ottawa, ON: Canadian Society for Exercise Physiology.

Coe, D. P., Pivarnik, J. M., Womack, C. J., Reeves, M. J., \& Malina, R. M. (2006). Effect of Physical Education and Activity Levels on Academic Achievement in Children. Medicine and Science in Sports and Exercise, 38,

1515-1519https://doi.org/10.1249/01.mss.0000227537.13175.1b

Cohen, J. (1988). Statistical Power Analysis for the Behavioral Sciences. London: Routledge Academic.

Datar, A., \& Sturm, R. (2004). Physical Education in Elementary School and Body Mass Index: Evidence from the Early Childhood Longitudinal Study. American Journal of Public Health, 94, 1501-1506. https://doi.org/10.2105/AJPH.94.9.1501

Dwyer, J. M., Allison, K. R., LeMoine, K. N., Adlaf, E. M., Goodman, J., Faulkner, G. E. J., \& Lysy, D. C. (2006). A Provincial Study of Opportunities for School-Based Physical Activity in Secondary Schools. Journal of Adolescent Health, 39, 80-86. https://doi.org/10.1016/j.jadohealth.2005.10.004

Faulkner, G., Goodman, J., Adlaf, E., Irving, H., Allison, K., \& Dwyer, J. (2007). Participation in High School Physical Education-Ontario, Canada, 1999-2005. Morbidity and Mortality Weekly Report, 56, 52-54.

Ferrer-Caja, E., \& Weiss, M. R. (2000). Predictors of Intrinsic Motivation among Adolescent Students in Physical Education. Research Quarterly for Exercise and Sport, 71, 267-279. https://doi.org/10.1080/02701367.2000.10608907

Fishburne, G. J., \& Hickson, C. (2005). What Is the Relationship between Physical Education and Physical Activity? City: Canadian Association for Health, Physical Education, Recreation and Dance.

Fryar, C. D., Carroll, M. D., \& Ogden, C. L. (2014). Prevalence of Overweight and Obesity among Children and Adolescents: United States, 1963-1965 through 2011-2012. National Center for Health Statistics. Atlanta, GA: Centre for Disease Control and Prevention.

Gibbons, S. L. (2009). Meaningful Participation of Girls in Senior Physical Education Courses. Canadian Journal of Education, 32, 222-244.

Hedley, A. A., Ogden, C. L., Johnson, C. L., Carroll, M. D., Curtin, L. R., \& Flegal, K. M. (2004). Prevalence of Overweight and Obesity among Us Children, Adolescents, and 
Adults, 1999-2002. The Journal of the American Medical Association, 291, 2847-2850. https://doi.org/10.1001/jama.291.23.2847

Hobin, E. P., Leatherdale, S. T., Manske, S. R., Burkhalter, R., \& Woodruff, S. J. (2009). A Multilevel Examination of School and Student Characteristics Associated with Physical Education Class Enrollment among High School Students. Journal of School Health, 80, 445-452. https://doi.org/10.1111/j.1746-1561.2010.00526.x

Hobin, E. P., Leatherdale, S. T., Manske, S. R., Burkhalter, R., \& Woodruff, S. J. (2010). A Multilevel Examination of School and Student Characteristics Associated with Physical Education Class Enrollment among High School Students. Journal of School Health, 80, 445-452.

IBM Corp (2011). IBM SPSS Statistics for Windows, Version 20.0. New York: IBM Corp.

Kruger, R. A. (1998a). Developing Questions for Focus Groups. Thousands Oaks, CA: SAGE Publications. https://doi.org/10.4135/9781483328126

Kruger, R. A. (1998b). Analyzing \& Reporting Focus Group Results. Thousands Oaks, CA: SAGE Publications. https://doi.org/10.4135/9781483328157

Luke, M. D., \& Sinclair, G. D. (1991). Gender Differences in Adolescents' Attitudes toward School Physical Education. Journal of Teaching in Physical Education, 11, 31-46. https://doi.org/10.1123/jtpe.11.1.31

Nassis, G. P., Psarra, G., \& Sidossis, L. S. (2005). Central and Total Adiposity Are Lower in Overweight and Obese Children with High Cardiorespiratory Fitness. European Journal of Clinical Nutrition, 59, 137-141. https://doi.org/10.1038/sj.ejcn.1602061

Nelson, M. C., Neumark-Sztainer, D., Hannan, P. J., Sirard, J. R., \& Story, M. (2006). Longitudinal and Secular Trends in Physical Activity and Sedentary Behavior during Adolescence. Official Journal of the American Academy of Pediatrics, 118, e1627e1634.

Public Health Agency of Canada (2012). Curbing Childhood Obesity; A Federal, Provincial and Territorial Framework for Action to Promote Healthy Weights. Ottawa: Public Health Agency of Canada.

Public Health Ontario: Ontario Agency for Health Protection and Promotion (2010). Taking Action to Prevent Chronic Disease: Recommendations for a Healthier Ontario. Toronto: Ontario Agency for Health Protection and Promotion.

Ryan, G. W., \& Bernard, H. R. (2003). Techniques to Identify Themes. Field Methods, 15, 85-109. https://doi.org/10.1177/1525822X02239569

Sallis, J. F., \& Patrick, K. (1994). Physical Activity Guidelines for Adolescents: Consensus Statement. Pediatric Exercise Science, 6, 302-302.

Standage, M., Duda, J. L., \& Ntoumanis, N. (2003) A Model of Contextual Motivation in Physical Education: Using Constructs from Self-Determination and Achievement Goal Theories to Predict Physical Activity Intentions. Journal of Educational Psychology, 95, 97-110. https://doi.org/10.1037/0022-0663.95.1.97

Statistics Canada (2010). Microdata User Guide: National Longitudinal Survey of Children and Youth. Ottawa: Statistics Canada.

Tassitano, R. M., Barros, M. V., Tenório, M., Bezerra, J., Florindo, A. A., \& Reis, R. S. (2010). Enrollment in Physical Education Is Associated with Health-Related Behavior among High School Students. Journal of School Health, 80, 126-133. https://doi.org/10.1111/j.1746-1561.2009.00476.x

Tesch, R. (1990). Qualitative Research: Analysis Types and Software Tools. London: Routledge.

Trudeau, F., \& Shephard, R. J. (2008). Physical Education, School Physical Activity, 
School Sports and Academic Performance. International Journal of Behavioural Nutrition and Physical Activity, 5, 10-22. https://doi.org/10.1186/1479-5868-5-10

Trudeau, F., Laurencelle, L., Tremblay, J. A., Rajic, M., \& Shephard, R. J. (1999). Daily Primary School Physical Education: Effects on Physical Activity during Adult Life. Medicine and Science in Sports and Exercise, 31, 111-117.

U.S. Department of Health \& Human Services (2013). Physical Activity Guidelines for Americans. Rockville, MD: U.S. Department of Health \& Human Services.

van Daalen, C. (2005). Girls' Experiences in Physical Education: Competition, Evaluation, \& Degradation. The Journal of School Nursing, 21, 115-121. https://doi.org/10.1177/10598405050210020901

Wechsler, H., Devereaux, A. B., Davis, M., \& Collins, J. (2000). Using the School Environment to Promote Physical Activity and Healthy Eating. Preventative Medicine, 31, S121-S137.

World Health Organization (2004). Global Strategy on Diet, Physical Activity and Health. Geneva: World Health Organization.

World Health Organization (2015). Commission on Ending Childhood Obesity. Geneva: World Health Organization. 


\section{Appendices}

\section{Appendix A. Glossary of Terms}

National Longitudinal Survey of Children and Youth (NLSCY)-is a longterm study of Canadian children that follows their development and well-being from birth to early adulthood. The study is designed to collect information about factors influencing a child's social, emotional and behavioural development and to monitor the impact of these factors on the child's development over time (Statistics Canada, 2010).

Cycle 7-NLSCY completed from September 2006 to July 2007.

Cycle 8-NLSCY completed from September 2008 to July 2009.

Non-School-Based Physical Activity (NSBPA) - Physical activity outside the school environment. Within this study, this variable consisted of physical activity outside of school, within the past 12 months, without a coach/instructor, with a coach/instructor, and physical activity through groups/lessons.

Physical Activity (PA) - the expenditure of energy as a result of bodily movement (Fishburne \& Hickson, 2005).

Physical Education (PE) - a school-based subject created to assist students in development of skills, knowledge, and attitudes vital for participation in active and healthy living (Fishburne \& Hickson, 2005).

PE Rating-participants rating of PE in comparison to Math, Science, English, French and Arts.

School-Based Physical Activity (SBPA) - Physical activity within the school environment, but outside of Physical Education class. Within this study, this variable consisted of school based physical activity, since the beginning of the year, without a coach/instructor, with a coach/instructor, and physical activity through groups/lessons. 


\section{Appendix B. Semi-Structured Question Guide}

1. Define the term: Physically Educated. What does that mean to you?

2. When you hear "Physical Education" what comes to your mind? Probe: Do you think it's hard for some students to get the PE credit?

3. Think back and recall your first experience of Physical Education in high school. What was your first impression?

Probe: Speak on behalf of a friend who isn't active. What kind of experience did they have?

4. What influenced your decision, or a friend's decision, to enroll or not enroll in Physical Education?

5. How would you feel about being required to take Physical Education for four years of high school? Probe: How do you feel about competitive versus non-competitive classes being offered?

6. List Task-students were provided with blank sheets of paper.

On one side of your paper list two items that you like about Physical Education, and on the other side of the paper list two items that you dislike about Physical Education.

Researcher collected the sheets and combined them into a list on chart paper within viewing distance of all participants.

b) Inventory-students copied the items listed on chart paper onto an inventory sheet that already included a list of potential likes/dislikes.

c) Ask yourself "Is this something that influences my Physical Education experience?" and give the item a score from 1 to 5 .

d) Which items did you agree or strongly agree with (4 or 5)?

e) Which items did you disagree or strongly disagree with? (2 or 1$)$ ?

7. Let me share some items that we haven't talked about, but were mentioned in previous focus groups.

The researcher lists the items that were not discussed and gives the students a chance to comment on them.

Probe: What do you think about some of the items that were already on the inventory?

8. Imagine that the subject of Physical Education was a person. What kind of person would they be?

9. If your job was to get students to enroll in Physical Education, what would you emphasize?

10. Review key questions and ideas that emerged.

b) What is important that we talked about today? Did we miss anything?

11. Students are given an evaluation form.

Scientific Research Publishing

\section{Submit or recommend next manuscript to SCIRP and we will provide best service for you:}

Accepting pre-submission inquiries through Email, Facebook, LinkedIn, Twitter, etc. A wide selection of journals (inclusive of 9 subjects, more than 200 journals)

Providing 24-hour high-quality service

User-friendly online submission system

Fair and swift peer-review system

Efficient typesetting and proofreading procedure

Display of the result of downloads and visits, as well as the number of cited articles

Maximum dissemination of your research work

Submit your manuscript at: http://papersubmission.scirp.org/

Or contact ape@scirp.org 